\title{
The Parotoplana jondelii species-group (Platyhelminthes: Proseriata): a microturbellarian radiation in the Mediterranean
}

\author{
Valentina Delogu ${ }^{1,3}$, Marco Curini-Galletti ${ }^{2}$ \\ 1,2 Dipartimento di Zoologia e Genetica Evoluzionistica, Università di Sassari, via Muroni 25, I-07100 Sassari, Italy \\ ${ }^{3}$ E-mail:vdelogu@uniss.it
}

Key words: biodiversity, meiofauna, new species, Parotoplana, taxonomy, vicariance

\begin{abstract}
Seven new Parotoplana species (Proseriata: Otoplanidae) from the Mediterranean, belonging to the $P$. jondelii complex, are described. They are characterized by the presence of numerous (14-22) copulatory spines. These are characteristically broad, and arranged in a girdle around the distal portion of the ejaculatory duct. In most species, dorsal and ventral spines are distinctly different from the rest of the spines of the girdle. This morphology of the copulatory spines is apomorphic for the genus Parotoplana, and supports a close relationship among these species. The new species ( $P$. axi sp. n., $P$. crassispina sp. n., P. carthagoensis sp. n., $P$. gracilispina sp. n., $P$. ichnusae sp. n., P. obtusispina sp. n., P. pulchrispina sp. n.) are distinguished by number and shape of the copulatory spines, and presence/absence of bursal spines. Species of the $P$. jondelii complex are at present only known from their type localities, and, at most, from adjacent areas. Only P. crassispina n. sp. is known to present a wider distribution in north-western Mediterranean, although populations across the range appear morphologically differentiated. The restricted, non-overlapping ranges of most species of the complex are suggestive of allopatric speciation.
\end{abstract}

\section{Contents}

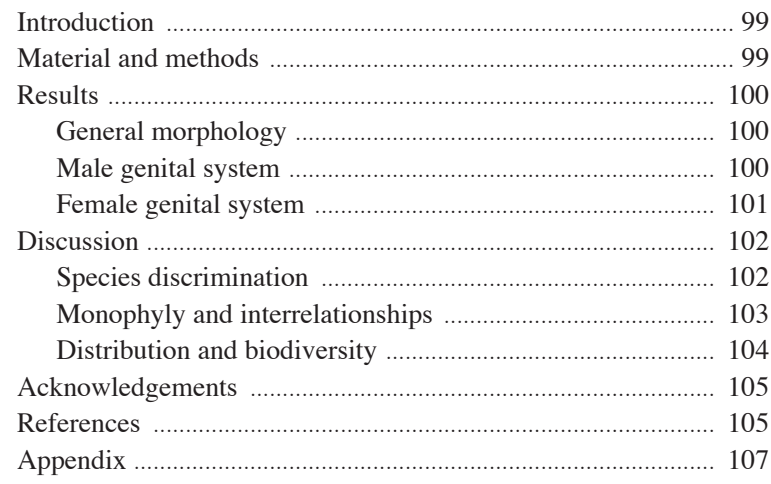

\section{Introduction}

The genus Parotoplana Meixner, 1938, which includes 15 species in the Mediterranean alone, is the most species-rich of the family Otoplanidae Hallez, 1892 (Platyhelminthes: Proseriata) (Delogu and Curini-Galletti, 2009). The genus appears heterogeneous as to the shape of body and pharynx, presence/absence of bursal nozzles and the proximal/distal fusion of the oviducts. Morphology of the copulatory spines in particular is extremely variable. The high number and morphological diversity of the species presently included in the genus suggest that careful re-examination is required.

Recently, under the sponsorships of the project 'Biodiversity of Inconspicuous Organisms in Marine Protected Areas' (BIOIMPA), a series of sampling campaigns were carried out along the Mediterranean coasts, aimed to gather data on the composition and distribution of a taxon of microturbellarians, viz the Platyhelminthes Proseriata. Description of the numerous new Parotoplana species found in the BIOIMPA samples, so far only marginally accomplished (Delogu and Curini-Galletti, 2007; 2009; Delogu et al., 2008), may thus help to throw light on the monophyly of the genus, and elucidate intra-group relationships.

The present contribution focusses on a group of Parotoplana species provided with a distinctive sclerotised apparatus, similar to that present in Parotoplana jondelii Delogu and Curini-Galletti, 2007 - henceforth called the $P$. jondelii species-group - of which seven new species are described.

\section{Material and methods}

Specimens were collected in sandy habitats by scooping up the superficial layer of sediment. Extraction of the animals from the sediment was done with $\mathrm{MgCl}_{2}$ decantation (Martens, 1984). Each species was first studied alive by slight squeezing under the cover-slip. Preservation techniques routinely adopted for Proseriata were used (see Martens et al., 1989b); whole 
mounts were made with lactophenol. For microscopical analysis material was fixed in Bouin's fluid, embedded in $60^{\circ} \mathrm{C}$ Paraplast and serial sagittal sections were cut at $4 \mu \mathrm{m}$, stained with Hansen's haematoxylin and eosin-orange and mounted in Eukitt.

The karyotype was determined from acetic orcein stained spermatogonial mitoses, as described by Curini-Galletti et al. (1989). Relative lengths (r. 1. = length of chromosome $\square$ 100/total length of haploid genome) and centrometric indices (c. i. = length of short arm $\square$ 100/length of entire chromosome) were obtained from measurements of camera lucida drawings of metaphase plates. The fundamental number (FN) (i.e. the number of chromosome arms in the karyotype) is derived according to Matthey (1949) and the chromosome nomenclature employed is that of Levan et al. (1964): $\mathrm{m}=$ metacentric; $\mathrm{sm}=$ submetacentric; $\mathrm{st}$ $=$ subtelocentric; $\mathrm{t}$ : acrocentric.

Type material is deposited in the collections of the Swedish Museum of Natural History (Stockholm, Sweden) (SMNH). Additional material, when present, is deposited in the collection of the Zoological Museum of the University of Sassari (Italy) (CZM).

Abbreviations used in figures are: a: atrium; b: bursa; bc: bursal canal; bn: bursal nozzles; br: brain; cm: circular musculature; cp: common genital pore; cs: copulatory spine; fd: female duct; fg: female glands; g: gut; gl: gut lumen; lm: longitudinal musculature; ov: ovary; ph: pharynx; pv: prostatic vesicle; r: rhabdoid gland; sf: sensory furrow; st: statocyst; sv: seminal vesicle; t: testis; tr: "transverse ridge"; vi: vitellaria.

\section{Results}

General morphology (Fig. 1)

All species of the Parotoplana jondelii species-group have a flattened body, comparatively short and broad for the genus. Fixed specimens average $1 \mathrm{~mm}$ in length. The anterior end is provided with a ciliated sensory furrow, several tactile bristles and a few adhesive papillae. The encapsulated, oval-shaped brain (about $64 \mu \mathrm{m}$ in diameter in P. carthagoensis sp. n.) abuts the statocyst, which contains two nuclei. The fan-shaped caudal end is provided with numerous adhesive papillae. A ciliated creeping sole runs from the sensory furrow to the level of the genital pore. The length of the cilia ranges from about $5 \mu \mathrm{m}$ (P. carthagoensis) to $7 \mu \mathrm{m}$ (P. pulchrispina sp. n.).

The epithelial cells, with intraepithelial nuclei, are cubical ventrally and more flattened dorsally. Differences between ventral and dorsal surfaces are most marked in P. pulchrispina sp. n., where their height is $5 \mu \mathrm{m}$ and $2-2.5 \mu \mathrm{m}$, respectively.

Rhabdoids are arranged in numerous (15-20), more or less regular, rows. They are narrow and rod shaped, 5-12 $\mu \mathrm{m}$ long.

Body musculature consists of a very thin outer circular layer, and of a much more developed inner longitudinal layer. This latter is particularly strong ventrally. Only in P. jondelii and P pulchrispina dorsal longitudinal fibres are well developed. Dorso-ventral muscle fibres are present anteriorly, just in front of the statocyst.

The pharynx, located in the middle of the body, is short and tubular. Its orientation can quickly shift from being placed horizontally to vertically, when it appears collar-shaped. Fixed specimens may present either condition. The pharynx is ciliated both internally and externally. External cilia are shorter than the inner cilia, ranging 1-1.5 $\mu \mathrm{m}$ and 2-2.5 $\mu \mathrm{m}$ in length, respectively. The distal tip, where pharyngeal glands discharge, is unciliated. No oesophageal area could be detected.

Male genital system (Figs 1,2)

Species of the complex have few (five to ten) pairs of testes in the anterior half of the body, arranged into

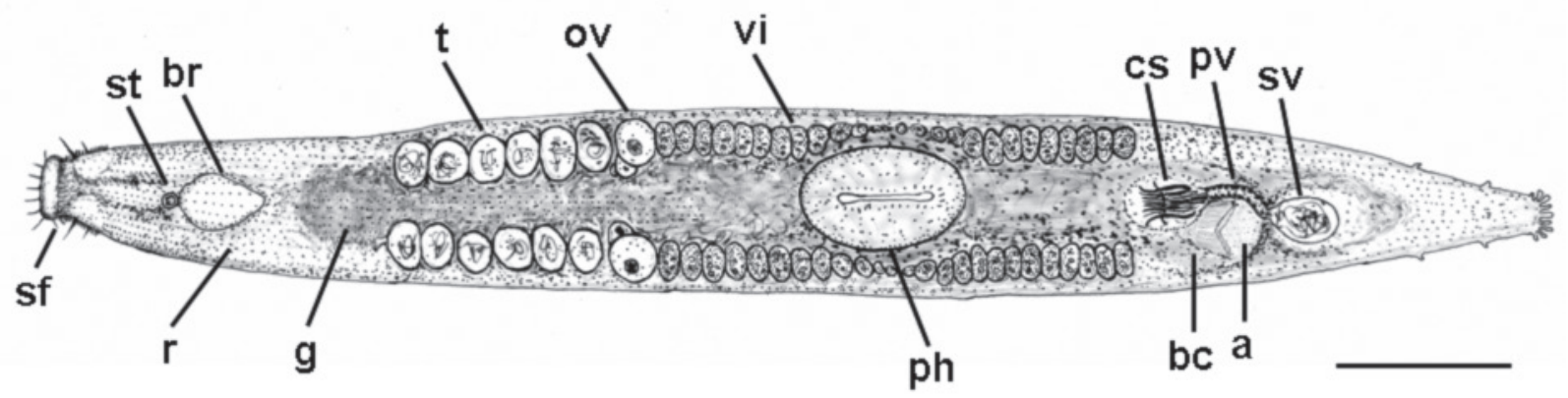

Fig. 1. Parotoplana crassispina sp. n. General organisation as seen in a slightly squeezed specimen. Scale bar: $100 \mu \mathrm{m}$. 
two regular rows. The copulatory organ consists of an ovoid seminal vesicle and a prostatic vesicle which is distally connected to the sclerotised apparatus. The seminal vesicle is lined by a thin nucleated epithelium, and is surrounded by a fine, spiral musculature. The shape of the prostatic vesicle is ovoid to elongated, depending upon the contraction during fixation. It ranges from 30-40 $\mu \mathrm{m}$ in length in $P$. crassispina sp. $\mathrm{n}$. to $20 \mu \mathrm{m}$ in P. carthagoensis. Its epithelium is ciliated, high and glandular, and is surrounded by very weak circular muscles.

The sclerotised apparatus consists of a girdle of spines, which, in most cases, are unusually broad and flat compared to other species of the genus Parotopla$n a$. The morphology and the number of these spines proved to be diagnostic features for species recognition within the complex, and will be described in detail in the appendix. In general, the spines are symmetrically arranged in pairs. The dorsal pairs of spines (D) are straight and have a simple, needle-like morphology. Usually, they consist of a central thinner, needlelike pair (indicated in species descriptions as $\mathrm{D}_{1}$ ). These are flanked by members of a much broader pair $\left(\mathrm{D}_{2}\right)$, tapering distally into a point.

Ventrally, a central pair of spines (V) is present. In most instances, these spines are quite distinct from the rest of the set, and are provided with a subterminal apophysis which, unlike in other species of Parotoplana, can be very large and flat.

Between the dorsal and ventral pairs, a series of spines, usually with a different morphology, are present. They are termed in the descriptions that follow as spines of the girdle $(\mathrm{G})$, and are numbered progressively, starting from the pair $\left(\mathrm{G}_{1}\right)$ closest to the dorsal pairs. In some of the species, $G_{1}$ spines are somewhat intermediate in morphology between dorsal spines and the rest of the spines of the girdle. In these instances, distinguishing between the dorsal and girdle spines is clearly arbitrary. Similarly, the girdle spines close to the ventral pair may be differently shaped than the others - particularly so in P. pulchrispina, where $\mathrm{V}$ spines are similar in morphology to the inner spines of the girdle.

The apophyses are attached to bundles of muscles. In P. crassispina, these bundles are particularly strong, and the movement of the apophyses is easily appreciable in semi-squashed living specimens.

\section{Female genital system (Figs 1, 2)}

Oocytes were observed in living specimens and in sections just posterior to the testis follicles. The vitel-

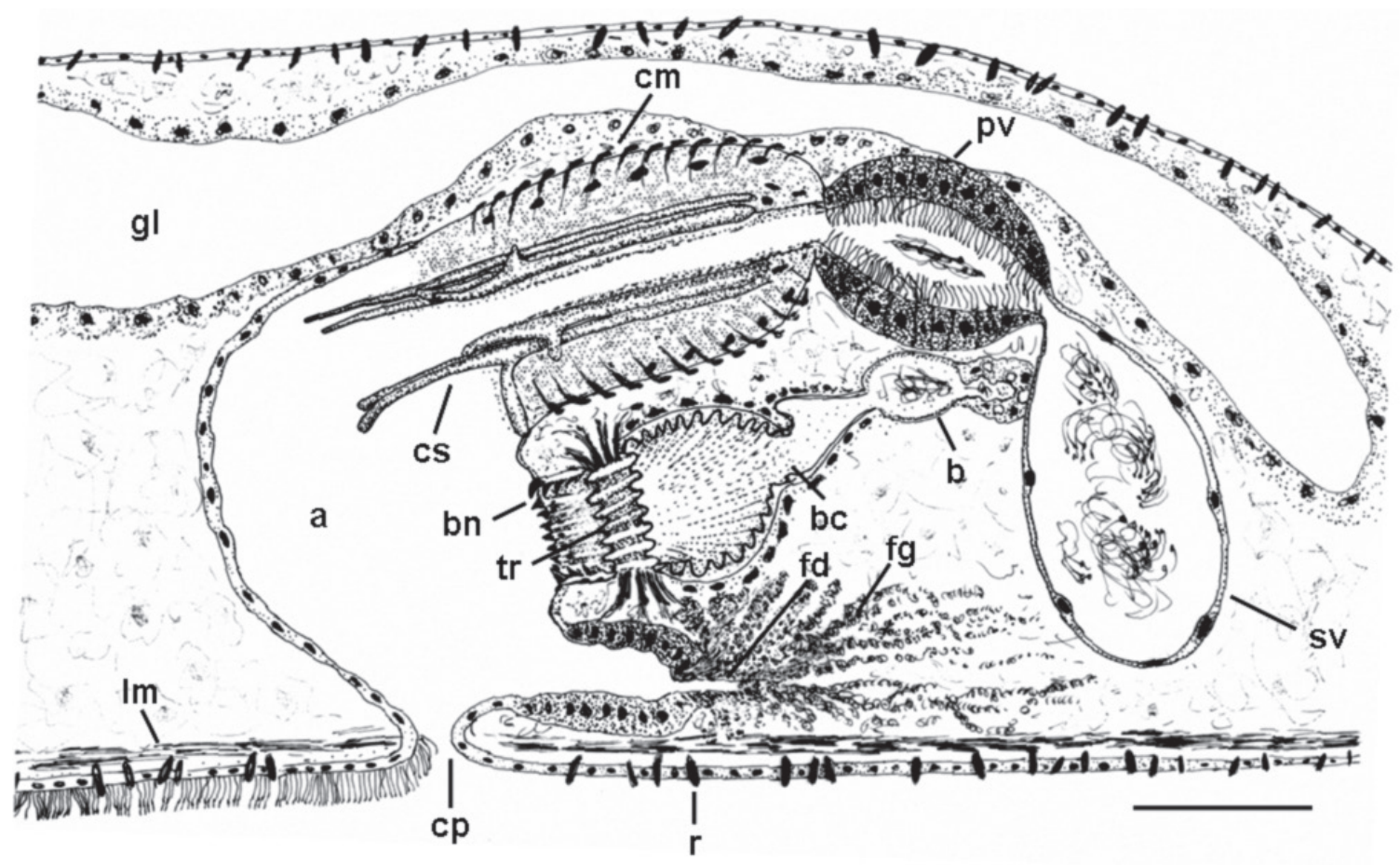

Fig. 2. Parotoplana crassispina sp. n. Reconstruction of the genital organs from sagittal sections. Scale bar: $20 \mu \mathrm{m}$. 
laria were almost equally distributed anteriorly and posteriorly to the pharynx. Most specimens of $P$. crassispina and $P$. carthagoensis, for example, had about 10-14 follicles in each area. P. pulchrispina had more posterior follicles (about 10) than the anterior ones (six). Only P. ichnusae sp. n. had markedly more anterior (about 20) than posterior (seven) vitellarian follicles; the living specimen studied appeared somewhat immature, however.

The female duct, formed by the fusion of the two oviducts, could be traced only close to its outlet in the lowermost, posterior area of the genital atrium. Its opening is surrounded by the outlets of female glands, whose bodies extend considerably into the caudal region. Both in P. crassispina and P. carthagoensis, the opening of the female duct is located in a pocket of the atrium, lined by a high epithelium.

The bursal system is complex and appears heterogeneous in morphology in the species-group. In $P$. crassispina, where the quality and quantity of the sectioned material allowed for a detailed reconstruction, the bursal system is particularly remarkable. Observations made on living specimens revealed an unusual, inverted-V shaped, striated structure close to the male copulatory organ (Figs 5C, D). Hardly squeezed karyological slides revealed the presence of a series of small triangular spines ('bursal nozzles'), often discernible as roughly arranged into two circles (Fig. 5A). The lack of surrounding nuclei suggests that these spines are basal lamina derivates, and not of an intracellular origin as the copulatory spines. In sectioned specimens, the striated, V-shaped structure is resolved as the two paired openings into the genital atrium of a wide bursal canal, provided with spines in its distalmost portion (Figs 2; $5 \mathrm{E}, \mathrm{F})$. The openings are separated by a transverse ridge, the core of which consists of a thick muscle bundle. These structures, including the bursal canal, are lined by a peculiar, deeply furrowed, infra-nucleated epithelium. It somehow resembles the 'pseudociliation' described for other Platyhelminthes (see Artois and Schockaert, 2001), but is much more regular in appearance, and with evenly spaced striae. These furrows correspond to the striae visible in living specimens. The outer bursal duct leads to a smooth inner portion, lined by what appears to be basal lamina, without overlaying epithelium, and which progressively narrows into a small, irregularly ovoid bursa, with a few chambers. The innermost chamber contained degenerating sperm, and may act as a bursa resorbiens.

Bursal spines are also found in P. jondelii (see Delogu and Curini-Galletti, 2007). In this species, they are arranged in two distinct blocks, suggesting that they may line the outlets of two independent bursal openings. However, in the sectioned material, only the outer, deeply furrowed portion of the bursal canal could be confidently traced.

Observation of living specimens of $P$. carthagoensis revealed a single, tubular bursal structure. In the karyological slides, a girdle of spines, sometimes fused basally into a tube (as in the specimen in Fig. 5B) could be seen. Sectioned material was not adequate to reconstruct the fine details of the structure. However, the presence of a single opening, surrounded by spines, leading to an outer bursal canal, deeply and evenly furrowed, could be detected with confidence. Morphology of the inner bursal area appears similar to P. crassispina.

$P$. pulchrispina lacks bursal spines. Its bursal canal is formed by an outer, undivided portion, lined by corrugated epithelium, and an inner area lined by basal lamina, leading to a small bursa, similar to that of $P$. crassispina.

Observation made on living specimens of $P$. gracilispina sp. n. revealed the presence of a clearly distinguishable, striated, inverted V-shaped bursal system, similar to previous species. In the karyological slides, however, no bursal spines were detected.

No information is available on the bursal system for the other species, nor could bursal spines be detected in karyological slides. It should be noted, however, that at least in $P$. crassispina, where a larger sample could be studied, bursal canal and spines were only visible in fully mature specimens. The lack of these structures may thus be related to immaturity.

\section{Discussion}

\section{Species discrimination}

Distinction among the species of the Parotoplana jondelii group is possible on the basis of differences in number and morphology of the copulatory spines (Fig. 3 ) and presence/absence of bursal spines.

The most obvious combinations of characters which are diagnostic for the species of the complex are as follows:

P. jondelii: presence of bursal spines and high number (18) of copulatory spines. $G_{1}$ similar to $D_{2} ; G_{3}$ similar to $\mathrm{V}$, which are provided with a nearly straight apex, and an obtuse distal tip. The spines of the girdle are provided with small, subtriangular apophyses. With bursal spines. 
P. axi: overall similar to $P$. jondelii, but with fewer (16), shorter and slender spines. It differs also for $\mathrm{D}_{1}$ similar to $\mathrm{D}_{2}$, and both provided with recurved distal tips; $\mathrm{G}_{1}$ with falcate apices, and without any spine pair clearly corresponding to the peculiar $\mathrm{G}_{3}$ of $P$. jondelii. The species possesses unique $\mathrm{V}$ spines, provided with a proportionally very long, whip-like distal tip. Without bursal spines.

P. pulchrispina: with the highest number of copulatory spines in the group (20-22). $\mathrm{D}_{1}$ distinctly thinner than $D_{2} ; G_{7}$ and $G_{8}$ spines very characteristic, with pointed apices and short apophyses; the rest of the girdle spines with distinctive, obtuse apices and slender, upturned apophyses. Unique $\mathrm{V}$ spines, similar to the girdle spines, with reduced apophyses and obtuse distal tips. Without bursal spines.

P. obtusispina: with 14 spines, most of which have obtuse distal tips. $G_{1}$ and $G_{2}$ are straight, slightly inflated subapically, without apophyses. V spines nearly straight, with blunt apices and small, flap-like apophyses. Without bursal spines.

P. ichnusae: with 16 spines. Girdle spines are broad; $\mathrm{G}_{1}$ have very small apophyses, and are similar in morphology to $D_{2} . G_{2}$ have long, falcate apices. The species has slender $\mathrm{V}$ spines, with small falcate apices, and short, narrow, upturned apophyses. Without bursal spines.

P. crassispina: with 14 copulatory spines. $\mathrm{G}_{1}$ are short, nearly straight, with very small apophyses, $G_{2}-$ $\mathrm{G}_{4}$ are broader than in any species of the group, with comparatively short, broad, flat apophyses. The V spines are characteristic, with long and flat apophyses, and a more or less straight distal tip, variable in morphology in the populations studied. With bursal spines.

$P$. carthagoensis: with 14 spines; similar to $P$. crassispina, but with a distinctive shape of $\mathrm{G}_{2} ; \mathrm{G}_{1}$ are proportionally much longer and with more developed apophyses. The rest of the $\mathrm{G}$ spines are distinctly slimmer than the corresponding spines of P. crassispina. $\mathrm{V}$ spines with much shorter apophyses. With bursal spines.

P. gracilispina: with 14 spines; similar to $P$. carthagoensis, but with overall slender spines. $\mathrm{D}_{2}$ are thin, almost as broad as $D_{1} ; G_{2}$ proportionally even longer and thinner distal tip than in P. carthagoensis; $\mathrm{G}_{1}, \mathrm{G}_{3}$, $\mathrm{G}_{4}$ and $\mathrm{V}$ are provided with much longer and thinner apices. Bursal spines not observed.

Attribution of allopatric populations with distinct morphology of $\mathrm{V}$ spines to the single species $P$. crassispina (see Appendix), may be debatable. The conservative approach adopted reflects the lack of in- formation from geographically intermediate areas. Morphological divergence among the similar speciespair $P$. carthagoensis - P. gracilispina appears much more marked, involving almost any pair of the spines of the set, and is interpreted here as supporting their specific distinction.

Karyotype, when available, revealed a very similar morphology in the species of the complex, with, at the most, small differences in the values of centromeric indices. The only species recognisable by features of karyotype alone appears to be $P$. jondelii. In this species each of the three smallest pairs is isobrachial. In the other species, at least one pair is markedly heterobrachial.

\section{Monophyly and interrelationships}

The presence of a complete or partial girdle of copulatory spines is not a rare feature within the genus Parotoplana. However, the arrangement most commonly found in the genus differs from what is described above for the $P$. jondelii group. In the type species, Parotoplana capitata Meixner 1938 and in $P$. varispinosa Delogu, Casu and Curini-Galletti 2008, two pairs of spines lie distinctly above the other spines of the set. The rest of the spines form a crescentshaped, semicircular girdle. The distal tips of these spines range in morphology from needle-shaped to falcate, and the ventral-most pair is indistinguishable from the surrounding spines (Ax, 1956, Figs 140-143, p. 717; Delogu et al., 2008, Fig. 2B, p. 167). In the observations carried out on living, semi-squashed specimens, the dorsal group appears distinct and obliquely set, with a different orientation than the other spines (Ax, 1956, Fig. 139, p. 717).

Similarly, in the P.turgida Ax and Ax, 1974 group, which includes one species from Galápagos and four species from Bermuda (Ax and Ax, 1974; Ax and Sopott-Ehlers, 1987), one or two dorsal spines, according to the species considered, lie above a semicircular girdle. In this species group, all spines have a similar morphology. Moreover, the dorsal spines are visible in living, semi-squashed specimens as a distinct group, obliquely oriented with respect to the rest of the set.

The complex sclerotised apparatus of $P$. terpsichore Delogu and Curini-Galletti, 2007 is formed by a complete girdle of numerous (46) spines. In addition, a pair of spines, dorsal to the girdle, is present. In this species, most spines are fine and slender and lack apophyses (Delogu and Curini-Galletti, 2007). 
A comparable arrangement to that described above for the P. turgida group is found in Parotoplanella progermaria Ax, 1956 (Ax, 1956; Figs 178-183, p. 733) - a possible sister-group of Parotoplana.

In most of the other species of Parotoplana, the ejaculatory duct is connected distally to a stylet, formed in general by two gutter shaped spines, often fused basally, or even for their entire length. The rest of the spines are lateral to the stylet (e.g., P. procerostyla Ax, 1956; see Ax, 1956; Fig. 175, p. 728), or form a semicircular girdle (e.g., P. macrostyla Lanfranchi, 1978; see Lanfranchi, 1978; Fig. 1A, p. 250).

There are thus no indications that the sclerotised set found in the $P$. jondelii group, i.e. a circular, complete girdle with the dorsal groups aligned with the rest of the set and with spines arranged in symmetrical pairs with different morphologies, is the plesiomorphic condition for the genus Parotoplana. This arrangement is thus assumed here to define a monophyletic group within the genus.

Species of the $P$. jondelii group present other unique characters:

- the wide bursal canal, bifurcated at least in $P$. crassispina, lined by a peculiar, furrowed, infranucleated epithelium is not known for other species of the genus. In most of them, in fact, the canal is narrow and elongated and lined by a flat epithelium with intraepithelial nuclei (see e.g., Ax, 1956; Fig. 150, p. 718);

- besides the P. jondelii species-group the karyotypes of other eight Parotoplana species are known. $P$. macrostyla, $P$. cucullata Delogu, Casu and CuriniGalletti 2008, P. pythagorae Delogu and CuriniGalletti 2007 and P. renatae Ax 1956 share the same haploid chromosome number $(\mathrm{n}=6)$ with the $P$.jondelii group. However, only two pairs of larger chromosomes are present in the karyotypes of these species, while the remaining pairs are distinctly smaller (Curini-Galletti et al., 1984; Delogu and Curini-Galletti, 2007; Delogu et al., 2008; Martens et al., 1989a). On the contrary, all species of the P. jondelii group have a karyotype with three large isobrachial chromosomes and three very small pairs, almost one third the length of the previous ones.

However, the lack of information about the above characters for some of the species of the $P$. jondelii group makes us refrain from considering them as further synapomorphies for the complex.

A further peculiar character, found in many species of the $P$. jondelii group, namely the presence of bursal spines, is on the contrary fairly widespread in species of Parotoplana and even present in the type species of the genus (see Ax, 1956; Fig. 143, p. 717; Fig. 150, p. 718). The occurrence of 'bursal nozzles' in apparently unrelated species of Parotoplana (Delogu et al., 2008) suggests that the character may indeed be plesiomorphic for the genus. Furthermore, the bursal spines may be easily overlooked in semi-squashed observations and in sections, and their presence even more widespread than reported at present. Exemplary in this respect is the case of P. rosignana Lanfranchi and Melai, 2008, where the bursal nozzles, which in this species constitute a very obvious tube with a flaring opening (Delogu and Curini-Galletti, 2009), are not even mentioned in the original description of the species (Lanfranchi and Melai, 2008).

Although the present state of knowledge does not allow inferences to be drawn on the polarity of the characters seen in the $P$.jondelii group, the sister-taxon relationship between $P$. carthagoensis and $P$. gracilispina is apparent. In fact, they share a peculiar morphology of G2 spines not found in any other species of the group. These two species have the same number and similar overall morphology of copulatory spines of $P$. crassispina, which may indeed be closely related to them.

\section{Distribution and biodiversity}

Species of the $P$. jondelii complex are common constituents of meiofaunal communities of mediumgrained sediments in shallow water. The group appears restricted to the central and eastern Mediterranean; none of the species were found in the BIOIMPA samples obtained from the northern Adriatic or along the Spanish coasts. In most areas, only one species of the group appears to be present. Exceptional in this regard is a beach in Sardinia, Le Bombarde, where three species of the complex (P. crassispina, P. pulchrispina, $P$. ichnusae) were found sympatrically in sediment samples taken at about $2 \mathrm{~m}$ deep. However, only $P$. crassispina was consistently present in the samples taken in shallower water, up to the intertidal zone.

The distributional pattern of the species of the group is indeed remarkable. P. crassispina is in fact the only species known for a wide range across the north-western Mediterranean. However, morphological divergence among populations is noticeable. P. ichnusae has been found in two localities on the west coast of Sardinia, about $50 \mathrm{~km}$ apart. The rest of the species are at present only known from their type locality, and have not been found even in apparently suitable substrates in 
adjacent areas. This limited distribution appears unusual even for the genus Parotoplana, where at least a few species present wider ranges across the central Mediterranean (Delogu and Curini-Galletti, 2009).

Owing to the present limited state of knowledge on biogeography of interstitial flatworms, the distributional data should be interpreted with caution. In fact, they depend on the scale of samplings performed so far, which is spotty at best. It is, however, significant that in most of the areas sampled during the BIOIMPA campaigns, different species of the complex were found, suggesting that ranges of these species may indeed be limited. The combination of narrow, mostly non overlapping ranges and divergence among populations, as observed in P. crassispina, is suggestive of poor dispersal and speciation acting by allopatric processes. The distribution of the two sister species $P$. carthagoensis and $P$. gracilispina from southern Mediterranean coasts (Tunisia and Israel) is indeed not conflictual with their origin from a common ancestor by allopatry.

Speciation processes, responsible for the peculiar geographical scale of speciation of the P. jondelii complex, have been plausibly enhanced by biological features of interstitial flatworms (i.e. strong thigmotactism of adults, direct development, short generation times). It is thus plausible that the study of the BIOIMPA material will reveal that congruent distributional and speciation patterns are widespread in mediterranean proseriates.

\section{Acknowledgements}

The authors wish to thank Mehrez Gammoudi (Tunis) for making the collection of samples possible in Tunisia. The research benefited from a grant by the Italian Ministry of Research (MIUR PRIN-2007 'Approccio integrato all'identificazione dei Proseriati', and from the 'Centro di Eccellenza' of the University of Sassari.

\section{References}

Artois TJ, Schockaert ER. 2001. Interstitial fauna of the Galapagos: Duplacrorhynchinae, Macrorhynchinae, Polycystidinae, Gyratricinae (Platyhelminthes Polycystididae). Tropical Zoology 14: 63-85.
Ax P. 1956. Monographie der Otoplanidae (Turbellaria). Morphologie und Systematik. Abhandlungen der mathematisch-naturwissenschaftlichen Klasse 13: 1-298, 499-796.

Ax P, Ax R. 1974. Interstitielle Fauna von Galapagos V. Otoplanidae (Turbellaria, Proseriata). Mikrofauna des Meeresbodens 27: 573598.

Ax P, Sopott-Ehlers B. 1987. Otoplanidae (Plathelminthes, Proseriata) von Bermuda. Microfauna Marina 3: 261-281.

Curini-Galletti M., Galleni L, Puccinelli I. 1984. Karyological observation of Monocelis fusca, M. lineata (Monocelididae) and Parotoplana macrostyla (Otoplanidae). Helgoländer Meeresuntersuchungen 38: 171-178.

Curini-Galletti M, Puccinelli I, Martens PM. 1989. Karyometrical analysis of ten species of the subfamily Monocelidinae (Proseriata, Platyhelminthes) with remarks on the karyological evolution of the Monocelididae. Genetica 78:169-178.

Delogu V, Curini-Galletti M. 2007. New species of the genus Parotoplana Meixner, 1938 (Proseriata, Otoplanidae) from southern Apulia (Italy). Zootaxa 1529: 17-31.

Delogu V, Casu M, Curini-Galletti M. 2008. The genera Parotoplana Meixner, 1938 and Parotoplanella Ax, 1956 (Platyhelminthes: Proseriata) in southern Spain. Journal of Natural History 42: 157-176.

Delogu V, Curini-Galletti M. 2009. Otoplanidae (Platyhelminthes, Proseriata) from the northern Adriatic Sea. Meiofauna marina 17: 133-144.

Lanfranchi A. 1978. Morphology and taxonomy of two new otoplanids (Turbellaria, Proseriata) from the Ligurian Sea. Zoologica Scripta 7: 249-254.

Lanfranchi A, Melai M. 2008. Parotoplana rosignana sp. nov.: Morphology, taxonomy and post-embryonal development of a new species of otoplanid (Plathelminthes, Rhabditophora, Proseriata). Italian Journal of Zoology 75: 197-206.

Levan A, Fredga K, Sandberg AA. 1964. Nomenclature for centrometric position on chromosomes. Hereditas 52: 201-220.

Martens PM. 1984. Comparison of three different extraction methods for Turbellaria. Marine Ecology Progress Series 14: 229-234.

Martens PM, Curini-Galletti M, van Oostveldt P. 1989a. Polyploidy in Proseriata (Platyhelminthes) and its phylogenetical implications. Evolution 43: 900-907.

Martens PM, Curini-Galletti M, Puccinelli I. 1989b. On the morphology and karyology of the genus Archilopsis (Meixner) (Platyhelminthes, Proseriata). Hydrobiologia 175: 237-256.

Matthey R. 1949. Les chromosomes des Vertèbrès. Lausanne: Rouge, 344.

Received: 18 March 2009

Accepted: 4 August 2009

Published online: 16 October 2009

Editor: R. Sluys 

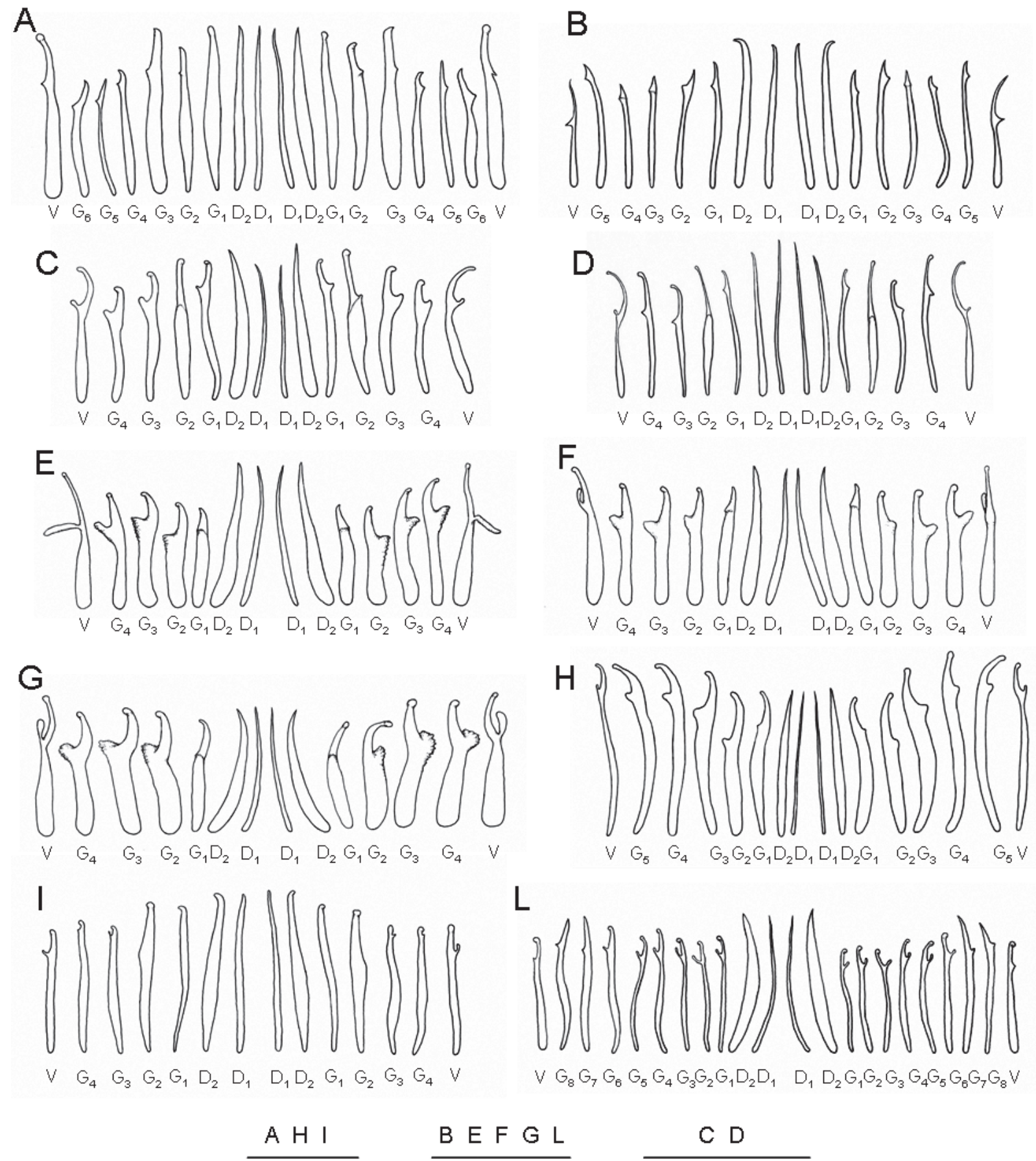

Fig. 3. Male sclerotised apparatus of Parotoplana jondelii (A); P. axi (B); P. carthagoensis (C); P. gracilispina (D); P. crassispina (from Castiglione della Pescaia (E), Canet (F), Le Bombarde (G)); P. ichnusae (H); P. obtusispina (I); P. pulchrispina (L). See text for spine labelling. Scale bars: $50 \mu \mathrm{m}$. 


\section{Appendix}

Family OTOPLANIDAE Hallez, 1892

Subfamily PAROTOPLANINAE Ax, 1956

Genus Parotoplana Meixner, 1938

Parotoplana jondelii Delogu and Curini Galletti, 2007 (Fig. 3A)

Material examined: two whole mounts (SMNH 6666 - holotype; CZM 55) and one specimen sagittally sectioned (CZM 56) from the type locality: Santa Maria di Leuca (Lecce, Apulia, Italy), La Principessa cave, about $5 \mathrm{~m}$ deep in coarse sand, May 2005.
Description: The sclerotised apparatus of this recently described species (Delogu and Curini-Galletti 2007), is here re-drawn and re-described, using the terminology of the spine pairs presented above. The species has 18 spines, arranged as follows:

- Dorsal pairs: $\mathrm{D}_{1}$ : straight, needle like, thin spines, 75-79 $\mu \mathrm{m}$ long; $\mathrm{D}_{2}$ : much stouter, straight spines, 70-80 $\mu \mathrm{m}$ long.

- The girdle typically consists of 6 pairs of spines: $\mathrm{G}_{1}$ : similar in size and shape to $\mathrm{D}_{2}$, but with blunt apices; $G_{2}$ : two broad spines (62-65 $\mu \mathrm{m}$ long), stout, straight, with falcate apices and small submarginal apophyses; $\mathrm{G}_{3}$ : large straight spines, 75$83 \mu \mathrm{m}$ long, with straight distal tips, and small subterminal apophyses; $\mathrm{G}_{4}-\mathrm{G}_{6}$ : three pairs of compara-
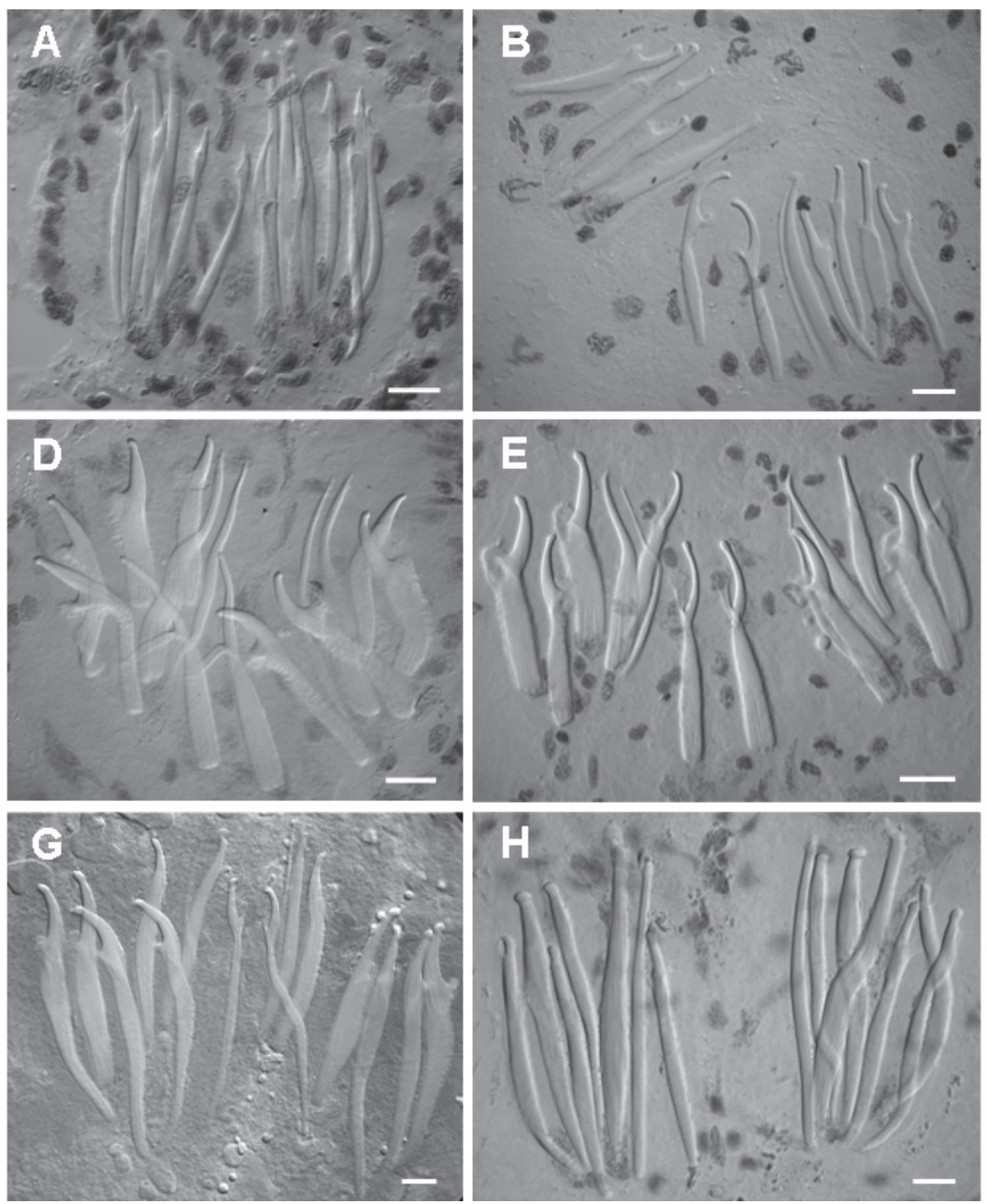
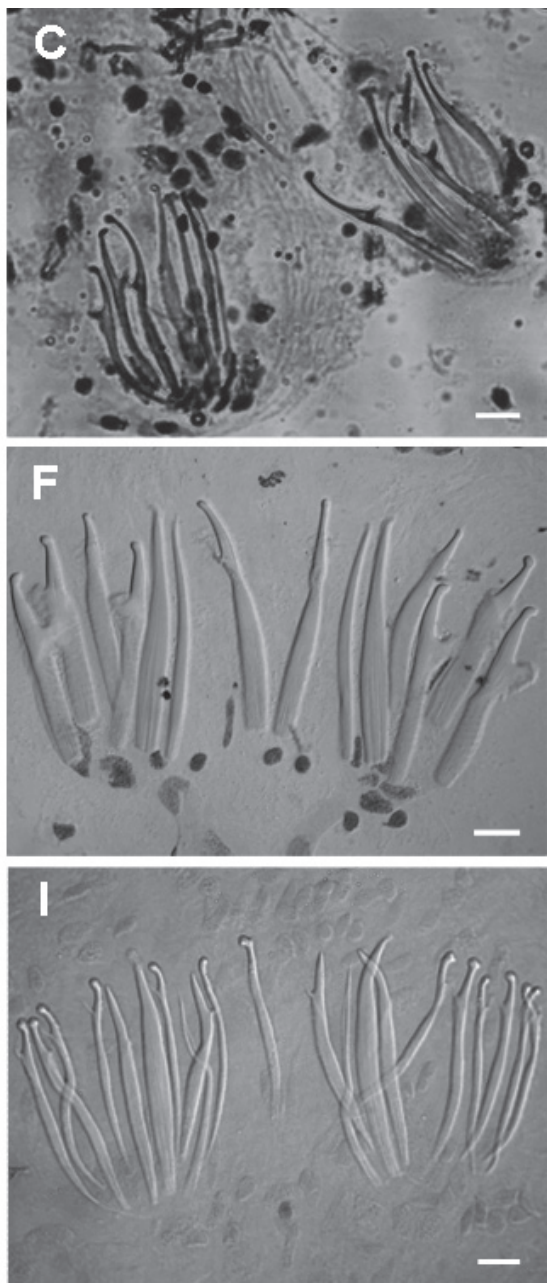

Fig. 4. Male sclerotised apparatus of Parotoplana axi (A) (holotype); P. carthagoensis (B) (holotype); P. gracilispina (C) (holotype); P. crassispina (holotype, from Castiglione della Pescaia (D); from Le Bombarde (E); from Canet (G)); P. ichnusae (G) (holotype); P. obtusispina (H) (holotype); P. pulchrispina (I)(holotype). Scale bars: $10 \mu \mathrm{m}$. 

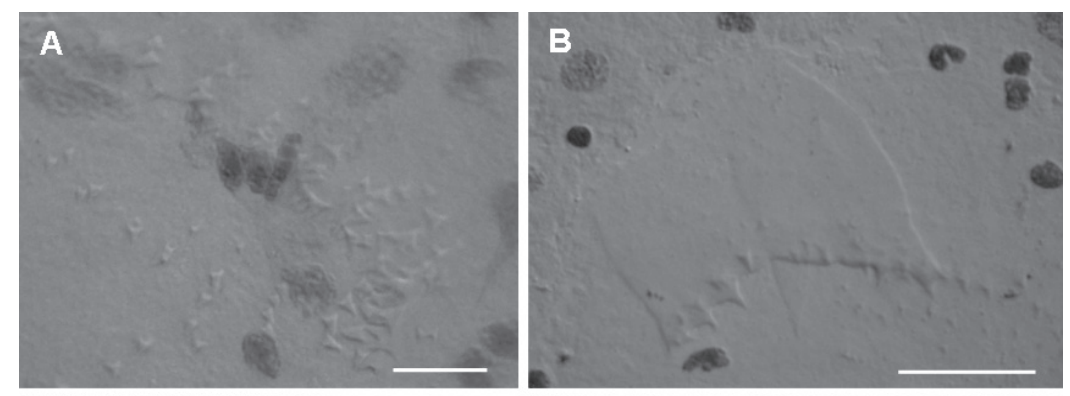

Fig. 5. A-B. Bursal sclerotised apparatus ("nozzles"). A: Parotoplana crassispina (from Castiglione della Pescaia); B: P. carthagoensis. C-F. Genital area of P. crassispina. C-D: from living, slightly squeezed specimens (C: Le Bombarde; D: Castiglione della Pescaia). E-F: from sagittal sections of specimens from Castiglione della Pescaia. Scale bars: A, B: $10 \mu \mathrm{m}$; C-F: $25 \mu \mathrm{m}$.
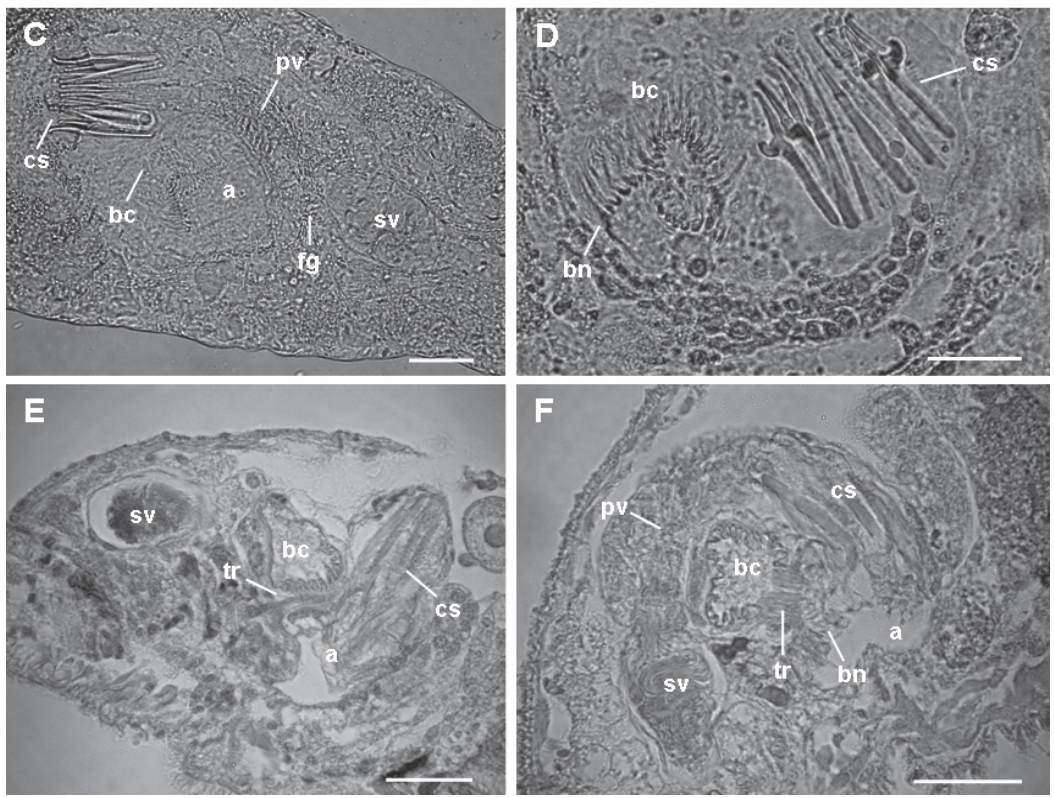

tively small spines (53-55 $\mu \mathrm{m}$ long), with apices progressively longer from $\mathrm{G}_{4}$ to $\mathrm{G}_{6}$; $\mathrm{G}_{5}$ distinctly slender and straighter than the other pairs.

- V: similar in size to $\mathrm{G}_{3}$ but with longer, more recurved distal tips, with distinctly blunt apices and a more developed, downwards pointing, submarginal apophyses.

In whole mounts, the presence of numerous bursal spines, arranged into two blocks, could be detected. These spines are sharply triangular in shape (up to 4-5 $\mu \mathrm{m}$ long), and weakly sclerotised (Delogu and CuriniGalletti, 2008, Fig. 7B, p. 29).

Karyotype. Chromosome number: $\mathrm{n}=6$; $\mathrm{FN}=12$. All chromosomes are isobrachial; the first three pairs are metacentric and distinctly larger than the remaining pairs, at the border between meta- and submetacentric chromosomes. Full karyometrical data are available in Delogu and Curini-Galletti, 2007.

Remarks. The species is only known from the type locality, a marine cave in southern Apulia (Italy), about $5 \mathrm{~m}$ deep in medium-coarse sand (Delogu and CuriniGalletti, 2007)
Parotoplana axi sp. n.

(Figs 3B; 4A)

Holotype: one karyological slide made permanent with lactophenol (SMNH 7573).

Type locality: Catania, Agnone (Sicily, Italy) (lat. $37^{\circ} 18^{\prime} 38.03$ ”'N, long. $15^{\circ} 6^{\prime} 24.63$ 'E); lower intertidal, medium-coarse sand, October 2008.

Etymology: the species is dedicated to dr. prof. Peter Ax (Göttingen, Germany), for his long-lasting contribution to the study of the Otoplanidae.

Description: Sclerotised apparatus consisting of 16 spines:

- $\quad D_{1}-D_{2}$ : dorsal spines are similar: both pairs are slender, 50-52 $\mu \mathrm{m}$ long, tapering into an acute, outwardly curved point, particularly evident in $\mathrm{D}_{2}$. As in all the species of the group, $\mathrm{D}_{1}$ is thinner (maximum width: $1,5 \mu \mathrm{m})$ than $\mathrm{D}_{2}$ (max. width: about $3 \mu \mathrm{m}$ ).

- $G_{1}-G_{5}$ : the girdle consists of five pairs of slender spines, with maximum width of stem about $2 \mu \mathrm{m}$, and length ranging from 39 to $46 \mu \mathrm{m}$. All have falcate distal tips, conical at least in $\mathrm{G}_{4}$ and $\mathrm{G}_{5}$, and 
small, triangular apophyses.

- V: distinctive spines, about 49-51 $\mu \mathrm{m}$ um long, provided with an apex 17-21 $\mu \mathrm{m}$ long, tapering into a narrowly elongate distal tip, and a small $(1.5 \mu \mathrm{m}$ long) apophysis. Stem about $4 \mu \mathrm{m}$ broad at its basis, narrowing to $1.5 \mu \mathrm{m}$ just below the apophysis.

Parotoplana carthagoensis sp. $\mathrm{n}$.

(Figs 3C; 4B; 5B)

Holotype: One specimen prepared as a whole mount (SMNH 7566).

Type locality: Sidi Bou Said (Tunis, Tunisia), (lat. $36^{\circ} 51$ '59.62”N, long. $10^{\circ} 20^{\prime} 52.74$ 'E), about $20 \mathrm{~cm}$ deep in medium sand, March 2008.

Paratype: one specimen sagittally sectioned (SMNH 7567).

Additional material: nine specimens sagittally sectioned (CZM 168-176) and two karyological slides (CZM 177-178), all from the type locality.

Etymology: the name refers to the type locality, adjacent to the ruins of the ancient city of Carthago.

Description: The sclerotised apparatus consists of 14 spines (13 in specimen CZM 177, 15 in specimen CZM 178) (Fig. 1B):

- Dorsal pairs: $\mathrm{D}_{1}$ : very slender, straight spines (only one in CZM 177), 40-45 $\mu \mathrm{m}$ long in the holotype, ranging 38-45 $\mu \mathrm{m}$, with a maximum width of $1 \mu \mathrm{m}$; $\mathrm{D}_{2}$ : stout and broader spines, 43-50 $\mu \mathrm{m}$ long (holotype $46-50 \mu \mathrm{m}), 4-5 \mu \mathrm{m}$ wide at their bases, tapering distally into a sharp point.

- Girdle: $\mathrm{G}_{1}$ : two spines, 39-40 $\mu \mathrm{m}$ long in the holotype (range $37-45 \mu \mathrm{m}$ ), 2-3 $\mu \mathrm{m}$ thick, with falcate apices and pointed distal tip. They are provided with small apophyses, located at about $8 \mu \mathrm{m}$ from the tip; $\mathrm{G}_{2}$ : two distinctive, straight spines, 40-47 $\mu \mathrm{m}$ long (holotype 43-45 $\mu \mathrm{m}$ ), with long, straight apices, with obtuse distal tips, and sharp, upturned apophyses placed at about $14 \mu \mathrm{m}$ from the tip; $\mathrm{G}_{3}$ $\mathrm{G}_{4}$ : two pairs of spines (five spines in specimen CZM 176), 37-39 $\mu \mathrm{m}$ in the holotype, ranging 37 $41 \mu \mathrm{m}$ in length and 3-4 $\mu \mathrm{m}$ wide, with falcate apices and obtuse distal tips, and short, broad apophyses placed at about $9 \mu \mathrm{m}$ from the distal tip.

- V: two spines, ranging 40-45 $\mu \mathrm{m}$ in length (holotype about $40 \mu \mathrm{m}$ ), and $3 \mu \mathrm{m}$ broad, with long falcate apices and blunt distal tip; apophysis flat, rather well developed (3-5 $\mu \mathrm{m}$ long) placed at about 12 $\mu \mathrm{m}$ from the tip.

The species is provided with numerous, broadly triangular bursal spines, 2 to $3 \mu \mathrm{m}$ in length, 3 to $4 \mu \mathrm{m}$ wide at their bases, arranged in concentric girdles, that, in a few specimens, are fused into a single tube, about $25 \mu \mathrm{m}$ long and $20 \mu \mathrm{m}$ wide (Fig. 4 B).

Karyotype. Chromosome number: $\mathrm{n}=6 ; \mathrm{FN}=11$. The first three pairs of chromosomes are distinctly larger than the three remaining pairs. Karyometrical data (based on measurements of three plates): Chrom. $\mathrm{I}=$ r.1.: $26.09 \pm 1.44$; c.i.: $44.95 \pm 0.96$ (m); Chrom. II $=$ r.l.: $25.48 \pm 1.11$; c.i.: $33.92 \pm 0.7$ (sm); Chrom. III = r.1.: $23.6 \pm 1.68$; c.i.: $42.41 \pm 1.48(\mathrm{~m})$; Chrom. IV $=$ r.1.: $9.02 \pm 1.41$; c.i.: $30.74 \pm 6.42(\mathrm{sm})$; Chrom. $\mathrm{V}=$ r.1.: $8.32 \pm 0.86$; c.i.: $45.27 \pm 2.54(\mathrm{~m})$; Chrom. VI = r.l.: $7.42 \pm 1.28$; c.i.: $10.41 \pm 2.97(\mathrm{t})$; haploid genome length: $7.4 \pm 0.5 \mu \mathrm{m}$.

Remarks. A common species in shallow water in the Sidi Bou Said harbour area, but not found elsewhere during extensive samplings performed along the Tunisian eastern coast during BIOIMPA campaign (2008).

Parotoplana crassispina sp. $\mathrm{n}$.

(Figs 1; 2; 3E-G; 4D-F; 5A, C-F)

Holotype: one whole mount (SMNH 7568).

Type locality: Castiglione della Pescaia, Capo Capezzolo (Tuscany, Italy) $\left(42^{\circ} 45^{\prime} 55.29^{\prime} \mathrm{N}\right.$, long. $\left.10^{\circ} 51^{\prime} 46.11^{\prime \prime} \mathrm{E}\right)$; lower intertidal, medium sand, March 2007.

Paratype: one specimen from the type locality sagittally sectioned (SMNH 7569).

Additional material: Tuscany: Castiglione della Pescaia, Capo Capezzolo. Six specimens sagittally sectioned (CZM 121-126) and four karyological slides made permanent with lactophenol (CZM 127-130), March 2007. Punta Ala, Torre Civette (lat. $42^{\circ} 50^{\prime} 41.70^{\prime \prime} \mathrm{N}$, long. $10^{\circ} 46^{\prime} 30.34$ 'E), lower intertidal, medium to coarse sand. 14 specimens sagittally sectioned (CZM 131-144) and eight karyological slides made permanent with lactophenol (CZM 145152), March 2007. Sardinia: Le Bombarde beach, Alghero (lat. $40^{\circ} 35^{\prime} 2.59^{\prime \prime} \mathrm{N}$, long. $8^{\circ} 15^{\prime} 37.36^{\prime \prime} \mathrm{E}$ ), in medium to coarse sand, from the lower intertidal to about $2 \mathrm{~m}$ deep. One specimen sagittally sectioned (CZM 153 ) and five karyological slides made permanent with lactophenol (CZM 154-158). Several specimens observed alive, July 2006. Archi Cave, Capo Caccia (lat. $40^{\circ} 34^{\prime} 10.71^{\prime \prime} \mathrm{N}$, long. $8^{\circ} 13^{\prime} 43.93^{\prime}$ 'E), medium sand, about $10 \mathrm{~m}$ deep. One specimen made as whole mounth (CZM 159), July 2006. Girin beach, Carloforte Is. (lat. $39^{\circ} 6^{\prime} 56.68^{\prime \prime} \mathrm{N}$, long. $\left.8^{\circ} 18^{\prime} 33.33^{\prime \prime} \mathrm{E}\right)$, about $50 \mathrm{~cm}$ deep, medium sand. Three specimens made as whole mount (CZM 160-162), June 2008. France: Canet, 
city beach (lat. 4241'41.36”'N, long. 3²'14.98’'E), about $2 \mathrm{~m}$ deep, medium sand. Five specimens made as whole mounts (CZM 163-167), August 2008.

Etymology: from latin crassus, fat - with reference to the peculiar, broad spines of the new species.

Description: With 14 copulatory spines, arranged as follows:

- Dorsal pairs: $D_{1}$ : thin, straight, needle-shaped spines, ranging $45-58 \mu \mathrm{m}$ long in specimens from Tuscany (holotype: 56-58 $\mu \mathrm{m}$ ) with maximum width at the basis of about $2.5 \mu \mathrm{m}$; and $42-48 \mu \mathrm{m}$ and 51-53 $\mu \mathrm{m}$ long in specimens from Sardinia (Le Bombarde) and Canet, respectively; $\mathrm{D}_{2}$ : broad, straight spines, ranging 47-64 $\mu \mathrm{m}$ long (holotype: $59 \mu \mathrm{m}$ ) and 6-7 $\mu \mathrm{m}$ broad at their basis (Tuscany); 42-50 $\mu \mathrm{m}$ long, $4.5 \mu \mathrm{m}$ broad (Sardinia); 53-56 $\mu \mathrm{m}$ long, $6 \mu \mathrm{m}$ broad (Canet).

- Girdle: $\mathrm{G}_{1}$ : short, straigth spines with slightly falcate, conical apices, provided with very small apophyses, ranging 37-44 $\mu \mathrm{m}$ long, 5-6 $\mu \mathrm{m}$ wide (Tuscany) (Holotype: 41-44 $\mu \mathrm{m}$; distance between apophysis and tip about $8.5 \mu \mathrm{m}$; stem $5.5 \mu \mathrm{m}$ wide); 37-43 $\mu \mathrm{m}$ long, $4.5 \mu \mathrm{m}$ wide (Sardinia); 41-46 $\mu \mathrm{m}$ long, $4.5 \mu \mathrm{m}$ wide (Canet). Sardinian specimens have a comparatively longer (about $1 / 3$ of the whole length of the spine) distal tip; $\mathrm{G}_{2}-\mathrm{G}_{4}$ : three pairs of broad spines, with characteristic flat and broad apophyses, falcate distal tips and blunt apices. Stems become progressively longer from $\mathrm{G}_{2}$ to $\mathrm{G}_{4}$, and spines gradually assume a more slender shape. Lengths range 32-52 $\mu \mathrm{m}$ long (Holotype: $42-50 \mu \mathrm{m}$ ), stem 3.5-6.5 $\mu \mathrm{m}$ broad, length of apex 11-13 $\mu \mathrm{m}$ (Tuscany); 37-46 $\mu \mathrm{m}$ long, 3.5-5 $\mu \mathrm{m}$ wide, length of apex 9-14.5 $\mu \mathrm{m}$ (Sardinia); 42-47 $\mu \mathrm{m}$ long, 3.5-5 um wide, length of apex 11-12 $\mu \mathrm{m}$ (Canet).

Ventral spines differ in morphology among populations. In Tuscan specimens, $\mathrm{V}$ spines are 47-65 $\mu \mathrm{m}$ long (holotype: $58-59 \mu \mathrm{m}$ ), $7.5 \mu \mathrm{m}$ broad at their bases, with straight, very long (18-24 $\mu \mathrm{m})$ distal tips, and long (11-20 $\mu \mathrm{m})$ and flat apophyses. Sardinian and French specimens have more recurved and comparatively shorter distal tips, and shorter, ovoid apophyses. Ranges are 47-55 $\mu \mathrm{m}$ long, $7 \mu \mathrm{m}$ broad, distal tip 11-19 $\mu \mathrm{m}$ long, apophysis 9-12 $\mu \mathrm{m}$ long (Sardinia) and 51-53 $\mu \mathrm{m}$ long, 5-6 $\mu \mathrm{m}$ broad, distal tip 12-17 $\mu \mathrm{m}$ long; apophysis 6-8 $\mu \mathrm{m}$ long (Canet).

With numerous bursal spines, arranged in girdles. Each girdle consists of up to 30 broadly triangular spines, with acute tips, increasing in length from proximal (about $1 \mu \mathrm{m}$ ) to distal (about $5 \mu \mathrm{m}$ ) girdles (Fig. $5 \mathrm{~A})$. The arrangement of spines is somewhat variable.
In a few specimens they are arranged into a single structure, consisting of about six girdles of spines. In other specimens girdles are less regular, while in others two distinct series of girdles are apparent. However, the level of the variability (either individual or interpopulational) has yet to be ascertained.

Karyotype. Chromosome number: $\mathrm{n}=6$; $\mathrm{FN}=10$. The first three pairs of chromosomes are distinctly larger than the three remaining pairs. Karyometrical data were obtained from two populations. Castiglione della Pescaia (Tuscany): Chrom. I = r.1.: $25.46 \pm 2.86$; c.i.: $35.4 \pm 1.79(\mathrm{sm})$; Chrom. II = r.1.: $24.03 \pm 0.84$; c.i.: $41.52 \pm 3.28(\mathrm{~m})$; Chrom. III = r.1.: $23.35 \pm 0.61$; c.i.: $32.39 \pm 2.53(\mathrm{~m})$; Chrom. IV = r.1.: $9.85 \pm 1.13$; c.i.: $36.95 \pm 4.59(\mathrm{sm})$; Chrom. V = r.1.: $8.72 \pm 0.26$; c.i.: $15.93 \pm 4.39$ (st); Chrom. VI = r.1.: $8.61 \pm 1.57$; c.i.: $10.12 \pm 1.43(\mathrm{t})$; haploid genome length: $9.6 \pm 0.8$ $\mu \mathrm{m}$ (based on measurements of four plates). Le Bombarde (Sardinia): Chrom. I = r.1.: $25.47 \pm 2.43$; c.i.: $44.08 \pm 2.09(\mathrm{~m})$; Chrom. II = r.1.: $25.32 \pm 2.63$; c.i.: $40.06 \pm 0.84(\mathrm{~m})$; Chrom. III = r.l.: $24.67 \pm 0.36$; c.i.: $33.15 \pm 2.57(\mathrm{~m})$; Chrom. IV = r.1.: $8.66 \pm 0.97$; c.i.: $20.8 \pm 4.08$ (st); Chrom. V = r.l.: $8.43 \pm 1.41$; c.i.: $39.15 \pm 2.73(\mathrm{~m})$; Chrom. VI = r.1.: $7.45 \pm 0.55$; c.i.: $8.97 \pm 0.95(\mathrm{t})$; haploid genome length: $10.1 \pm 0.9 \mu \mathrm{m}$ (based on measurements of five plates).

Remarks. A shallow water species, often common in medium-grained sediments up to the low water mark. In this habitat, it may be the numerically dominating proseriate, as in the Tuscan sites.

$P$. crassispina is the only species of the group known for a comparatively broad range, extending across the north-western Mediterranean region. Populations in this range appear to differ noticeably, particularly in the morphology of $\mathrm{V}$ and $\mathrm{G}_{1}$ spines. The suspicion that different species have been lumped into a single taxon, may thus arise. However, the range of variation of the spines, and thus the reliability as diagnostic markers of the differences observed, should be assessed on more adequate geographical sampling than that presently available. At the moment, given the overall similarity of most spine pairs across the range, and the overlap in measures among populations, differences in morphology are assumed to reflect a degree of interpopulational (clinal?) divergence.

Parotoplana gracilispina sp. $\mathrm{n}$. (Figs 3D; 4C)

Holotype: one karyological slide made permanent with lactophenol (SMNH 7599). 
Type locality: Atlit (Israel), beach near the Castle (lat. 32 42’21.01”N, long. 3456'6.90”E), lower intertidal, medium sand, February 1986.

Additional material: one karyological slide made permanent with lactophenol (CZM 184)

Etymology: the name refers to the slender (latin gracilis) appearance of the copulatory spines.

Description: The sclerotised apparatus consists of 15 spines in the holotype, and 14 in CZM 184:

- Dorsal pairs: $D_{1}$ : slender, straight, spines ranging 43-44 $\mu \mathrm{m}$ long, with a maximum width at their bases of $1 \mu \mathrm{m} ; \mathrm{D}_{2}$ : stouter spines, 47-51 $\mu \mathrm{m}$ long, about $3 \mu \mathrm{m}$ wide at their bases, tapering distally.

- Girdle: $\mathrm{G}_{1}$ : two spines, 37-39 $\mu \mathrm{m}$ long, 2-3 $\mu \mathrm{m}$ wide in their middle, tapering towards their bases. With slender, slightly falcate apices and obtuse distal tips. They are provided with small apophyses, located at about $7 \mu \mathrm{m}$ from the tip; $\mathrm{G}_{2}$ : two straight spines, $46-48 \mu \mathrm{m}$ long, about $4.5 \mu \mathrm{m}$ wide in their middle, and tapering basally to $1 \mu \mathrm{m}$ wide. With very long, slender, straight apices with obtuse distal tips, and with very small apophyses, placed at about $20 \mu \mathrm{m}$ from the apex; $\mathrm{G}_{3}-\mathrm{G}_{4}$ : ranging in length from 41-44 $\mu \mathrm{m}\left(\mathrm{G}_{3}\right)$ to $48-51 \mu \mathrm{m}\left(\mathrm{G}_{4}\right)$; stems $2-3 \mu \mathrm{m}$ wide in their middle. Both pairs have long, falcate apices, with obtuse distal tips and short apophyses placed at about $10-16 \mu \mathrm{m}$ from the distal tip.

- V: two spines, ranging 44-48 $\mu \mathrm{m}$ in length, and 2.5 $\mu \mathrm{m}$ broad, with very long, slender, falcate apices and blunt distal tip; apophysis flat, 3-3.5 $\mu \mathrm{m}$ long, placed at $17-20 \mu \mathrm{m}$ from the tip.

No bursal spines were retrieved in the specimens studied.

Karyotype. Chromosome number: $\mathrm{n}=6 ; \mathrm{FN}=10$. The first three pairs of chromosomes are distinctly larger than the three remaining pairs. Karyometrical data (based on measurements of nine plates): Chrom. I $=$ r.l.: $25.92 \pm 2.13$; c.i.: $37.13 \pm 0.91(\mathrm{sm})$; Chrom. II = r.1.: $24.6 \pm 1.42$; c.i.: $29.03 \pm 3.76(\mathrm{sm})$; Chrom. III = r.l.: $23.85 \pm 2.56$; c.i.: $45.24 \pm 1.27(\mathrm{~m})$; Chrom. IV = r.l.: $8.93 \pm 1.21$; c.i.: $18.07 \pm 5.91$ (st); Chrom. $\mathrm{V}=$ r.l.: $8.84 \pm 1.15$; c.i.: $28.48 \pm 5.81$ (sm); Chrom. VI = r.l.: $7.76 \pm 2.05$; c.i.: $12.18 \pm 5.81(\mathrm{t})$; haploid genome length: $11.4 \pm 0.9 \mu \mathrm{m}$.

\section{Parotoplana ichnusae sp. $\mathrm{n}$.}

(Figs 3H; 4G)

Holotype: one karyological slide made permanent with lactophenol (SMNH 7570).

Type locality: Le Bombarde beach, Alghero (Sar- dinia, Italy) (lat. $40^{\circ} 35^{\prime} 1.50^{\prime} \mathrm{N}$, long. $8^{\circ} 15^{\prime} 38.05^{\prime} \mathrm{E}$ ), about $2 \mathrm{~m}$ deep, medium-fine sand, May 2008

Additional material: Porto Alabe (Sardinia) (lat. $40^{\circ} 14^{\prime} 46.87^{\prime \prime} \mathrm{N}$, long. 8²8'28.49'”E), about $1.5 \mathrm{~m}$ deep, medium sand. One karyological slide made permanent with lactophenol (CZM 177), June 2008.

Etymology: the species epithet refers to the ancient greek name of Sardinia, Hyknusa (latinised as Ichnu$s a)$.

Description: With a sclerotised apparatus consisting of 16 spines:

- Dorsal pairs: $\mathrm{D}_{1}$ : two very thin, needle shaped, straight spines, $62 \mu \mathrm{m}$ long in the holotype (range 61-65 $\mu \mathrm{m}$ ), ending into a sharp distal tip. Stem about $1.5 \mu \mathrm{m}$ broad; $\mathrm{D}_{2}$ : two broad, straight spines, 62-64 $\mu \mathrm{m}$ long in the holotype (range 60-65 $\mu \mathrm{m}$ ) slightly tapering distally into a rather obtuse tip. Stem about $4.5 \mu \mathrm{m}$ thick.

- Girdle: $G_{1}$ : similar to $D_{2}$, but with a blunter apex, and with a very small apophysis $13-15 \mu \mathrm{m}$ from the slightly curved distal tip. $64 \mu \mathrm{m}$ long in the holotype, ranging 60-65 $\mu \mathrm{m}$; stem $5.5 \mu \mathrm{m}$ broad; $\mathrm{G}_{2}$ : transient between the morphology of $\mathrm{G}_{1}$ and the rest of the spines of the girdle. 63-65 $\mu \mathrm{m}$ long in the holotype (range 61-65 $\mu \mathrm{m}$ ) with a comparatively very long slightly curved apex, with an obtuse distal tip, and with a small apophysis at about $23 \mu \mathrm{m}$ from the apex. Stem $7.5 \mu \mathrm{m}$ broad at its maximum, about $5 \mu \mathrm{m}$ at its basis; $\mathrm{G}_{3}-\mathrm{G}_{5}$ : three pairs of rather similar spines, 76-80 $\mu \mathrm{m}$ long in the holotype (range 72-81 $\mu \mathrm{m})$ with falcate apices progressively shorter and with small, obtuse subterminal apophyses. Stems ranging 6-8 $\mu \mathrm{m}$ in width.

- V: slender spines (79-81 $\mu \mathrm{m}$ long in the holotype, ranging 70-81 $\mu \mathrm{m}$ ), with small falcate apices, and obtuse distal tips. They are provided with a narrow, upward turned apophysis, about $3 \mu \mathrm{m}$ long. The distance between apices and apophysis is about $12 \mu \mathrm{m}$. Stem about $4 \mu \mathrm{m}$ broad, narrowing to $1.5 \mu \mathrm{m}$ at its basis.

Without bursal spines.

Karyotype. Chromosome number: $\mathrm{n}=6$; $\mathrm{FN}=11$. The first three pairs of chromosomes are distinctly larger than the three remaining pairs. The only plate suitable for karyometric analysis from the specimen from Le Bombarde yielded the following data: Chrom. $\mathrm{I}=$ r.1.: 24.84; c.i.: 44.72 (m); Chrom. II = r.1.: 24.36; c.i.: $30.71(\mathrm{sm})$; Chrom. III = r.1.: 24.31; c.i.: 40.67 (m); Chrom. IV = r.1.: 9.32; c.i.: 31.83 (sm); Chrom. V = r.1.: 9.32; c.i.: 18.18 (st); Chrom. VI = r.1.: 8.75; c.i.: $46.37(\mathrm{~m})$; haploid genome length: $9.4 \mu \mathrm{m}$. 
Parotoplana obtusispina sp. $\mathrm{n}$.

(Figs 3I; 4H)

Holotype: one karyological slide made permanent with lactophenol (SMNH 7572).

Type locality: St. Cyprien, France (lat. 42 $37^{\prime}$ 45.97”N, long. $3^{\circ} 2$ ' $11.55^{\prime \prime E}$ ), about $2 \mathrm{~m}$ deep, medium sand, August 2008.

Additional material: three karyological slides made permanent with lactophenol (CZM 181-183).

Etymology: the name refers to the blunt (latin obtusus) apices of the spines.

Description: The sclerotised apparatus consists of 14 spines (15 in specimen CZM 181) arranged as follows:

- Dorsal pairs: $\mathrm{D}_{1}$ : straight spines, with obtuse distal tips, 70-72 $\mu \mathrm{m}$ long in the holotype, ranging 69-73 $\mu \mathrm{m}$ in the sample; stem about $3 \mu \mathrm{m}$ broad; $\mathrm{D}_{2}$ : straight spines, distinctly broader than $\mathrm{D}_{1}$, with a recurved, obtuse distal tip. 71-73 $\mu \mathrm{m}$ long in the holotype, ranging 70-73 $\mu \mathrm{m}$; stem about $7.5 \mu \mathrm{m}$ broad; narrowing basally to $2 \mu \mathrm{m}$.

- Girdle: $\mathrm{G}_{1}$ : straight spines, $63 \mu \mathrm{m}$ long in the holotype (range: 61-65 $\mu \mathrm{m}$ ), without apophysis, with very narrow bases (about $1 \mu \mathrm{m}$ broad), widening progressively to $4 \mu \mathrm{m}$ towards the subapical region. Apex provided with an obtuse distal tip. $\mathrm{G}_{2}$ : similar to $\mathrm{G}_{1}, 67 \mu \mathrm{m}$ long in the holotype, ranging $67-70 \mu \mathrm{m}$, with narrow bases, about $1.5 \mu \mathrm{m}$ wide, widening distally to a maximum width of $6 \mu \mathrm{m}$ at about $20 \mu \mathrm{m}$ from the apex, which is nearly straight, and provided with an obtuse distal tip. Without distinct apophysis. $\mathrm{G}_{3}-\mathrm{G}_{4}$ : two pairs of similar spines, about $60 \mu \mathrm{m}$ long, with a maximum width of the stem of 4-5 $\mu \mathrm{m}$, and narrowing towards a basis about $2 \mu \mathrm{m}$ wide. Both pairs have very short (about $5 \mu \mathrm{m}$ long) obtuse apices. With small apophyses, more developed in $\mathrm{G}_{4}$.

V: $55 \mu \mathrm{m}$ long in the holotype, ranging 54-59 $\mu \mathrm{m}$. Straight, rod-shaped spines, with a slightly recurved, obtuse distal tip. With a flat subterminal apophysis, inserted at about $13 \mu \mathrm{m}$ from the apex.

\section{Parotoplana pulchrispina sp. n.}

(Figs 3L; 4I)

Holotype: one karyological slide made permanent with lactophenol (SMNH 7571).

Type locality: Le Bombarde beach, Alghero (Sardinia, Italy) (lat. $40^{\circ} 35^{\prime} 1.50^{\prime \prime} \mathrm{N}$, long. $8^{\circ} 15^{\prime} 38.05^{\prime} \mathrm{E}$ ), in medium-fine sand, about $2 \mathrm{~m}$ deep, May, December 2008.
Additional material: two karyological slides made permanent with lactophenol (CZM 178-179) and one specimen sagittally sectioned (CZM 180), all from the type locality.

Etymology: the name refers to the graceful, elegant morphology of the spines (latin pulcher $=$ fine, beautiful).

Description: The sclerotised apparatus consists of numerous spines (21 in the holotype, 20 in CZM 178 and 22 in CZM 179).

- dorsal pairs $\mathrm{D}_{1}$ : two thin, needle shaped spines, 52$53 \mu \mathrm{m}$ long in the holotype (range: $46-53 \mu \mathrm{m}$ ); stem 2-3 $\mu \mathrm{m}$ wide; $\mathrm{D}_{2}$ : two broad, straight spines, tapering into an acute point, 55-56 $\mu \mathrm{m}$ long in the holotype (range: $51-56 \mu \mathrm{m}$ ); stem 4-5.5 $\mu \mathrm{m}$ wide in the middle, and about $3 \mu \mathrm{m}$ at its basis.

- Girdle: $\mathrm{G}_{1}-\mathrm{G}_{6}$ : A somewhat variable number of similar, straight spines (11 in the holotype, 12 in CZM 179,10 in CZM 178), ranging $42-54 \mu \mathrm{m}$ in length in the sample, with slightly falcate apex, ending into an obtuse distal tip, and narrow, upturned subterminal apophyses, 2-5 $\mu \mathrm{m}$ long. Stem width ranging 1.5-2.5 $\mu \mathrm{m} ; \mathrm{G}_{7}$ : a pair of spines with straight, pointed apex, and very small apophysis inserted at about $14 \mu \mathrm{m}$ from the distal tip. $49-50 \mu \mathrm{m}$ long in the holotype (range: $50-53 \mu \mathrm{m}$ ); stem $3-3.5 \mu \mathrm{m}$ wide in the middle, about $1.5 \mu \mathrm{m}$ at its basis; $\mathrm{G}_{8}$ : very similar to $\mathrm{G}_{7}$, but with more acute and slender, comparatively shorter (about $10 \mu \mathrm{m}$ long) apex. 44-46 $\mu \mathrm{m}$ long in the holotype, ranging $44-51 \mu \mathrm{m}$ in the whole sample; stem 3-3.5 $\mu \mathrm{m}$ broad.

- V: medially to pair $\mathrm{G}_{8}$, all specimens had a pair of smaller spines, similar in morphology to $G_{2}-G_{7}$ spines, but with straighter distal tip, and with very small, obtuse apophyses. In the holotype, these spines are 42-46 $\mu \mathrm{m}$ long, with a thin and feebly sclerotised stem. In the rest of the sample, they are about $46 \mu \mathrm{m}$ long, with a stem slightly widening towards its base, which is $3 \mu \mathrm{m}$ across.

Without bursal spines.

Karyotype. Chromosome number: $\mathrm{n}=6$; $\mathrm{FN}=10$. The first three pairs of chromosomes are distinctly larger than the three remaining pairs. Karyometrical data (based on measurements of four plates): Chrom. I $=$ r.l.: $25.23 \pm 1.19$; c.i.: $42.45 \pm 1.33(\mathrm{~m})$; Chrom. II = r.l.: $24.89 \pm 0.06$; c.i.: $38.01 \pm 1.46(\mathrm{~m})$; Chrom. III = r.l.: $24.02 \pm 1.24$; c.i.: $32.5 \pm 1.77$ (sm); Chrom. IV = r.l.: $8.39 \pm 0.65$; c.i.: $15 \pm 4.36$ (st); Chrom. $\mathrm{V}=$ r.l.: $8.13 \pm 0.98$; c.i.: $36.43 \pm 2.88(\mathrm{sm})$; Chrom. VI = r.l.: $7.68 \pm 0.74$; c.i.: $11.3 \pm 4.41(\mathrm{t})$; haploid genome length: $10 \pm 1 \mu \mathrm{m}$. 